\title{
Motion events in language and cognition
}

\author{
Silvia P. Gennari ${ }^{\mathrm{a}, *}$, Steven A. Sloman ${ }^{\mathrm{b}, *}$ \\ Barbara C. Malt ${ }^{\mathrm{c}}$, W. Tecumseh Fitch ${ }^{\mathrm{d}}$ \\ ${ }^{a}$ University of Maryland, Department of Linguistics, CNL Laboratory, College Park, MD 20242, USA \\ ${ }^{\mathrm{b}}$ Brown University, Department of Cognitive Linguistic Sciences, Providence, RI 02912, USA \\ ${ }^{\mathrm{c}}$ Lehigh University, Department of Psychology, Bethlehem, PA, USA \\ ${ }^{\mathrm{d}}$ Harvard University, Department of Psychology, Cambridge, MA, USA
}

Received 19 February 2000; received in revised form 12 September 2001; accepted 14 November 2001

\begin{abstract}
This study investigated whether different lexicalization patterns of motion events in English and Spanish predict how speakers of these languages perform in non-linguistic tasks. Using 36 motion events, we compared English and Spanish speakers' linguistic descriptions to their performance on two non-linguistic tasks: recognition memory and similarity judgments. We investigated the effect of language processing on non-linguistic performance by varying the nature of the encoding before testing for recognition and similarity. Participants encoded the events while describing them verbally or not. No effect of language was obtained in the recognition memory task after either linguistic or non-linguistic encoding and in the similarity task after non-linguistic encoding. We did find a linguistic effect in the similarity task after verbal encoding, an effect that conformed to languagespecific patterns. Linguistic descriptions directed attention to certain aspects of the events later used to make a non-linguistic judgment. This suggests that linguistic and non-linguistic performance are dissociable, but language-specific regularities made available in the experimental context may mediate the speaker's performance in specific tasks. (C) 2002 Elsevier Science B.V. All rights reserved.
\end{abstract}

Keywords: Whorfian hypothesis; Verb concept; Motion event; Lexicalization; English; Spanish; Recognition; Similarity; Path; Manner; Talmy

\section{Introduction}

What is the relation between talk about events and how people think about them? Linguistic studies of event structures and semantic representations have often invoked universal conceptual structures underlying different cross-linguistic verbal patterns (Jack-

\footnotetext{
* Corresponding authors.

E-mail address: sgen@wam.umd.edu (S.P. Gennari), stevensloman@brown.edu (S.A. Sloman).
} 
endoff, 1986, 1990; Talmy, 1983, 1985). However, little experimental work has investigated event concepts and their verbal counterparts. Most empirical work on the relation between linguistic and non-linguistic representations has concentrated on referential categories such as natural kinds, artifacts, and color terms (for review see Barsalou, 1992; Lucy, 1992). This paper describes research investigating the question of how non-linguistic conceptualizations of events, as opposed to objects, relate to their linguistic counterparts. Our starting point is the claim that English and Spanish speakers differ in their attention to specific aspects of motion events in both linguistic and conceptual tasks (Slobin, 1996a,b, 1998). Because any study of the relation between these tasks necessarily requires the consideration of both linguistic and non-linguistic data, we compared performance on a linguistic task with performance on two non-linguistic tasks: recognition memory and similarity judgments of motion events.

\subsection{Language and conceptualization: conflicting approaches and specific views}

Two general approaches can be identified in the literature concerning the nature of the relation between language and conceptualization. The universal approach, represented in the work of Jackendoff $(1986,1990)$, and typological work on language universals such as that of Greenberg (1966) and Comrie (1981) argues that conceptual structures are universal, i.e. identical across languages. As a result, the universal approach claims that crosslinguistic differences in verbal categories or syntactic constructions do not reflect conceptual but merely linguistic differences. Linguistic representations may instantiate universal concepts in different ways because the relation between linguistic and conceptual structures is complex and mediated by mapping rules or principles. In contrast, the languagebased approach, represented in work by Whorf (1956) and subsequent studies on the linguistic relativity hypothesis (e.g. Bloom, 1981; Brown \& Lenneberg, 1954; Levinson, 1994, 1996a,b; Lucy, 1993, 1996; Slobin, 1996a,b, 1998), argues that conceptual representations are not all universal. Language-specific categories may shape and be part of speakers' conceptualizations of experience.

Within the language-based approach, several distinct views can be identified. They differ in the way and circumstances in which language and thought are proposed to interact. One view is what we call the Strong Language-based view, represented by linguistic relativity proposals such as those of Brown and Lenneberg (1954), Lucy (1993), Bloom (1981), Levinson (1996a,b, 1997) and others. It holds that linguistic patterns may influence people's conceptualizations during language learning, shaping the schemata used to represent the environment. Consequently, non-linguistic cognitive processes will be closely linked to the form or the content of the language spoken. Language-specific names or obligatory grammatical markers will have stable, detectable effects on what aspects of the world are attended to and processed.

Another view within the language-based approach is what we will call the Weak Language-based view. This view suggests that linguistic influences on thought occur in special circumstances. Slobin (1996a,b), for example, argues that language may have an effect mainly on the processes of thinking for speaking, i.e. during the process of language production and interpretation, speakers must direct attention to those aspects of experience that their grammars obligatorily encode. Such aspects may be incorporated into habitual 
thought patterns associated with language processing. Thus, language may influence conceptualization of experience only when this experience is linguistically mediated. Other researchers have suggested that language may provide the means to encode and retrieve information in memory (Lantz \& Stefflre, 1964; Lenneberg \& Roberts, 1956) or the means to integrate information that cannot be integrated in other representational systems (Hermer-Vazquez, Spelke, \& Katsnelson, 1999).

Yet another language-based view is what we call the Language-as-Strategy view. This view suggests that speakers should be influenced by linguistic characteristics only when performing certain tasks in which language could plausibly serve to mediate performance. For example, people might appeal to linguistic regularities as a conscious or unconscious strategy to reach a decision that would otherwise be difficult to reach on the basis of nonlinguistic considerations. Along these lines, Kay and Kempton (1984) found that linguistic color category boundaries influenced people's color similarity judgments in situations in which a linguistic strategy (using names to guide choices) was potentially available. Colors named with different terms were judged as more different than those similarly named. However, the linguistic effect disappeared when the instructions led participants to avoid this strategy. This suggests that participants used information drawn from their linguistic classifications to make a difficult judgment.

In sum, researchers have typically adopted either the universal or the language-based approach, and within the latter, a number of specific proposals have been made. The question thus is open whether different languages simply instantiate underlying conceptual universals in different ways, or whether linguistic differences have cognitive consequences in some or all circumstances.

\subsection{Conflicting evidence}

Studies have provided evidence consistent with each of the two general approaches. Evidence consistent with the universal approach comes from studies of spatial cognition, object categorization, and color terms. In the domain of spatial cognition, Landau and Jackendoff (1993), Hayward and Tarr (1995), and others have suggested that visual representations of space may universally constrain spatial language. Landau and Jackendoff (1993), for example, point out that across languages, descriptions of spatial relations using expressions such as over, above, on, within, and in encode shape to a lesser extent than object names do, i.e. such relations are relatively independent of the shape of the objects being related. In contrast, object names make more fine-grained shape distinctions (compare bottle to jar to jug). They attribute these constraints on cross-linguistic verbalizations to the poverty of the underlying universal spatial representations relative to those of objects.

In the domain of color, Berlin and Kay (1969), Kay and McDaniel (1978), Heider (1971, 1972), Heider and Olivier (1972), and others have shown that despite differences in the number of color terms in different languages, color vocabularies are constrained by perceptual or semantic universals. For example, Berlin and Kay (1969) showed that basic color lexicons of the world's languages tend to denote certain prominent regions of the color array (foci) and develop in an orderly fashion to identify new foci. In the domain of object categorization, Malt, Sloman, Gennari, Shi, and Wang (1999) found that 
the linguistic classification of artifacts varies across languages. However, non-linguistic similarity judgments of the objects were strikingly similar across speakers of the different languages.

Evidence consistent with the language-based approach comes from studies related to the linguistic relativity hypothesis in domains such as language acquisition, spatial cognition, and color perception. Choi and Bowerman (1991) and Bowerman (1996), for example, argue that children are sensitive to language-specific biases in their development of spatial concepts. In their study of English and Korean children, they found that very young children adopt language-specific principles of semantic categorization. They also found little evidence for pre-linguistic universal principles different from language-specific ones. They concluded that the structure of the linguistic input plays an important role in the development of spatial concepts. In the domain of spatial cognition, Levinson (1994, 1996a,b, 1997) and Brown and Levinson (1993) found that different linguistic systems used to represent spatial location have cognitive consequences for their speakers. For example, Tzeltal (a Mayan language of Mexico) uses an absolute system of spatial reference (north vs. south), and its speakers behave accordingly when reproducing certain arrays of objects non-verbally. Levinson and colleagues concluded that despite the fact that spatial cognition may be constrained by cognitive universals, such constraints underdetermine the range of possible conceptual representations of space.

In the color domain, several studies argue for influences of color terms in recognition memory and discrimination (Brown \& Lenneberg, 1954; Davidoff, Davies, \& Roberson, 1999; Lantz \& Stefflre, 1964; Lenneberg \& Roberts, 1956; Roberson, Davies, \& Davidoff, 2000). For example, in a study comparing English and Berinmo speakers (a language spoken in Papua New Guinea), Davidoff et al. found better fits between color names and memory performance within a language than across languages. They also found that speakers of English and Berinmo were better at remembering cross-category colors than within-category colors.

Research in the domain of grammatical categories also provides evidence consistent with the language-based view. Sera, Berge, and Pintado (1994) and Lucy (1993) have shown an influence of grammatical elements such as gender and number marking on a speaker's conceptualizations. For example, Lucy (1993) exploited differences in the pluralization systems of English and Yucatec Maya to examine whether the presence or absence of grammatical markers influenced people's encoding of pictures. In English, substances are not typically marked for number but inanimate objects are. In contrast, in Yucatec, neither inanimate objects nor substances are marked for number. Lucy found that English speakers tended to make more recognition errors and to judge stimuli as more similar when the stimulus pictures varied in the number of substances included rather than in the number of objects. In contrast, Yucatec speakers' performance was similar when pictures varied in the number of inanimate objects and in the number of substances. This pattern is in agreement with the grammatical pattern in each language.

These conflicting pieces of evidence indicate that the nature of the relation between conceptualizations and language remains an open question. In the present study, we investigate this relation in the domain of motion events. Specifically, we ask whether different lexicalization patterns of motion events in English and Spanish have significance for how speakers of these languages perform on non-linguistic tasks. 


\section{Motion events in English and Spanish}

\subsection{Linguistic differences}

Following Talmy (1985) and subsequent research (Aske, 1989; Jackendoff, 1990; Levin \& Rappaport Hovav, 1992; Slobin, 1996a,b), verbs that express motion can be decomposed into basic conceptual elements. Motion verb meanings normally contain a Path (the direction of the movement), the Figure/agent of the movement, and the Manner of movement (e.g. walking vs. running). Talmy also distinguishes two types of languages that differ in the way they linguistically encode or lexicalize these components. In languages like English and other Germanic languages, motion verbs normally encode Manner of motion (for example, clamber, stride, creep, slip, sneak, stroll), using obligatory prepositional phrases or particles to indicate Path (up/down, in/out, into the house, out of the house). In contrast, in languages such as Spanish and other Romance languages, Turkish, and Hebrew, motion verbs typically express Path (in Spanish, entrar 'enter', salir 'exit', subir 'ascend', bajar 'descend'), using optional adverbial phrases to express Manner (entra caminando '(he) enters walking').

However, Talmy's generalization does not apply to all lexicalizations of motion events. In Spanish, Manner can be expressed when continuous actions such as running towards the store are lexicalized. The distinction must be circumscribed to culminated motion events, i.e. actions involving a change of state or location (Aske, 1989; Levin \& Rappaport Hovav, 1992; Slobin, 1996a,b). Because Spanish manner verb + preposition constructions cannot express culmination, ${ }^{1}$ culminated events must be reported with path verbs such as entrar/salir 'enter/exit', which are change-of-location verbs. These verbs typically entail the initial and final state of the change relative to some boundary, edge or reference object. For example, I exited the room entails that I was in the room and then I was out (Dowty, 1979, 1986).

Thus, speakers of English and Spanish differ in how they talk about the same observed change of location. Spanish speakers are forced by their language to use change-of-state path verbs, where the expression of Path is obligatory, whereas Manner is confined to an optional adverbial modifier. This pattern contrasts with that of English, which explicitly and obligatorily indicates Manner in the verb and Path in the adverbial particle. In sum, to talk about culminated events, English speakers typically encode both Manner and Path, while Spanish speakers encode Path in the verb and tend to omit Manner.

\subsection{Motion events and the conflicting views}

In the domain of motion events, the two approaches outlined earlier are represented by specific proposals. Jackendoff $(1990,1996)$ has proposed that English and Spanish share the same conceptual structures, but possess different rules mapping universal conceptual components onto their lexical structures. Such rules generate different syntactic and lexi-

\footnotetext{
${ }^{1}$ In Spanish manner verbs + prepositional phrases, the path phrase simply indicates the direction/location of a continuous movement (e.g. corre a la escuela, '(he) runs towards the school'). Path prepositions in Spanish cannot predicate the end-state of the trajectory as they do in English (e.g. 'He ran to school') (see Aske, 1989, for this point).
} 
cal packaging of shared conceptual elements such as Motion and Path. For example, they allow English to incorporate complete path information via a prepositional phrase into the basic conceptual structure of a manner of motion verb. Spanish, in contrast, lacks such rules so that completed Path does not occur with manner verbs, and path verbs are used instead. From a cross-linguistic viewpoint, English is the marked case, idiosyncratically incorporating Path with Manner. Thus, for Jackendoff, linguistic differences do not imply differences in underlying conceptual structures.

In support of this view, Jackendoff offers a learnability argument. On the one hand, if the English grammatical structure reflects the underlying universal conceptual structure, the Spanish restriction prohibiting a manner verb + path preposition to express culminated events would have to be learned on the basis of negative evidence. On the other hand, if Spanish reflects conceptual universal structure, the English case of manner verb + prepositional phrase can be learned on the bases of positive experience. Thus, Spanish grammatical structures must correspond to the universal conceptual structure, while English has a language-specific rule mapping the conceptual structure into the English pattern. This argument, however, although compelling, is not conclusive. It takes for granted that English and Spanish share conceptual structure and provides no independent evidence for this assumption. Therefore, the possibility remains that learning guides speakers of different languages to different conceptual systems. ${ }^{2}$

Studies of motion events taking the language-based approach are represented primarily by Slobin (1996a,b, 1997, 1998), in his thinking for speaking reformulation of the linguistic relativity hypothesis. Slobin argues that linguistic differences in language production and processing predispose speakers of different languages to pay attention to different aspects of experience. Consequently, he suggests that for English speakers, manner is a (habitual) target of attention (given the obligatory combination of motion with manner). He also suggests that for them it is more codable (because it is expressed with a single word) and is thus more frequent and cognitively available. In contrast, Spanish speakers are not led by their language to systematically attend to manner. In Spanish, manner is less frequently expressed, less codable (it comes at the additional cost of more syntactic constituents), and is thus less cognitively salient.

Evidence consistent with this language-based view comes from several studies carried out by Slobin (1996a,b, 1997). Slobin analyzed Spanish-English translations, Spanish and English narrations elicited by the same set of pictures, and the mental images associated with narrations in each language. He found that (a) manner of motion verbs are more numerous in English, (b) the availability of motion + manner in English has led to a highly elaborated set of contrasts in the domain of manner in English that Spanish lacks, (c) English narrators (children, adults and novelists) mention path and manner details more than Spanish ones, (d) Spanish translations of English motion events either reduce the full path-ground trajectory, allocate location information to static clauses, or omit the manner information, (e) manner is not normally mentioned in

\footnotetext{
${ }^{2}$ While this article was under review, it came to our attention that recent work by Papafragou, Massey, and Gleitman (2001) in the domain of motion events found no effects of language when comparing English and Greek speakers in linguistic and cognitive tasks. These results are thus consistent with Jackendoff's view in that conceptual organization is independent from linguistic patterns.
} 
Spanish unless relevant to or necessary for narrative purposes, and (f) Spanish speakers tend to mentally represent stories in static frames (as manifested by speakers' descriptions of their mental images). This has led to the development of a discursive style in Spanish by which speakers either imply location, omit manner, or represent it via descriptions of static images. These characteristics are attributed to the lesser focus on manner and greater focus on path in English and Spanish lexicalization patterns, respectively.

Studies by Billman, Swilley, and Krych (2000) and Billman and Krych (1998) have also provided evidence consistent with the language-based approach. They found that whether English speakers heard manner or path verbs when encoding motion events (e.g. walk vs. enter) affected their later recognition of the events: participants tended to be less sensitive to changes on the dimension that they had not verbally encoded. Although these studies only focused on verbs (rather than verb + particles) and did not take into account the canonical pattern of English, they suggest that the type of verb used during encoding of events can influence recognition by either helping retrieval or shaping encoding.

This body of evidence is suggestive but far from conclusive. Billman et al. (2000) and Billman and Krych (1998) did not investigate cross-linguistic differences. The use of a particular verb was also either given or induced by the experimenter, and the verb alone (not a phrase or sentence) was the only linguistic encoding of each event, making the linguistic encoding of the event more salient than it likely would be in normal production circumstances. In Slobin's studies, each response pattern observed was mediated by language, i.e. it constitutes linguistic rather than non-linguistic evidence. Speakers speak the way they do precisely because of the lexical restrictions characteristic of each language; it is largely pre-determined that English speakers will express more manner distinctions than Spanish speakers, and that, because path information is entailed rather than specifically described by the verb (e.g. be in or out), Spanish translators will express extra specific location information in a different phrase (e.g. be out of the house in the park). ${ }^{3}$ Different verbal descriptions by speakers of different languages need not imply different cognitive or conceptual representations at the non-linguistic level. Slobin's evidence thus does not directly speak to the question of whether English and Spanish speakers conceptualize events differently.

\subsection{Studying conceptualizations of motion events and their relation to language}

Discovering how events are mentally represented without appealing to language is difficult. However, a related question is easily posed, namely, how two non-linguistic event representations are related. For example, one can investigate how confusable two events are in memory or how people judge the similarity of two events. Recognizing an

\footnotetext{
${ }^{3}$ Change-of-state verbs are incompatible with specific locative phrases because they already entail the initial and final location relative to the ground object. Such entailments, however, do not specify the exact location of the agent. If further specifications are required about these locations or the trajectory between them, Spanish would express them in different clauses because the path verb cannot support elaboration on the semantic elements that it already entails. This is why Spanish speakers have trouble translating sentences such as I stroll across the park to the main building. One can translate this sentence as something like I crossed the park (walking leisurely) and arrived at the main building or I went to the main building that was across the park.
} 
event as "old" (previously encountered) requires comparing the properties of a target event with the properties of events stored in memory. To the degree that the comparison reveals many common and few distinctive properties, the target event is likely to be taken as old. Analogously, asserting that event A is more similar to event B than to some other event requires an assessment of the degree to which they have common and distinctive properties (Tversky, 1977). Thus, these tasks provide direct evidence about the extent of commonalities and differences between mental representations that may or may not be influenced by the properties emphasized by language.

However, recognition and perception of similarity are distinct from one another. Recognizing an event as one previously stored in memory is not necessarily a deliberate act. It can be carried out automatically by retrieval processes that give a sense of familiarity and can be accomplished in the absence of conscious awareness of familiarity with the stimulus (Mandler, 1980; Rajaram, 1993). In contrast, judging similarity in the absence of time constraints depends on aspects of the comparison process that may emerge after deliberation. This process often involves representational alignment, it generally gives greatest weight to the higher-order properties that unify the interpretation of the event (Medin, Goldstone, \& Gentner, 1993), and it is sensitive to a variety of task factors such as the weight of the features entering in the comparison, the directionality of the comparison (A similar to B vs. B similar to A) and the set of objects under consideration (Tversky \& Gati, 1978). In particular, similarity judgments have often been found to be influenced by category labels and linguistic markers: objects or events that share labels are perceived as more similar (see Goldstone, 1994a,b; Kurtz, 1996; Rothbart, Davis-Stitt, \& Hill, 1997; Zhang \& Schmitt, 1998; and research on color terms mentioned earlier). Together, these points suggest that perception of similarity may be more likely to show contextual influences than recognition memory, especially in situations where contextual elements such as the presence of linguistic labels is manipulated.

\section{Description of the study}

In this study, we investigated whether Spanish and English lexicalization patterns influence recognition memory and similarity judgments of 36 triads of videotaped events. Each triad contained a target and two alternate events in which the manner or path of the target event had been changed. Three different groups of participants performed these two tasks after different encoding conditions. In one condition (Naming First), the encoding manipulation explicitly encouraged the verbal encoding of the events by requiring participants to describe the events as they were presented. In the other two conditions, there was no explicit requirement of verbal encoding (the Free Encoding and Shadow conditions), but the amount of concurrent cognitive processing during encoding differed. In the Free Encoding condition, participants simply watched the 36 target events displayed on a computer screen. In the Shadow condition, participants repeated nonsense syllables while watching the videos. This condition was designed to minimize linguistic processing of the events and to decrease memory performance by loading verbal working memory during encoding. In all conditions, after encoding, participants performed a recognition memory task, where target items as well as alternate items were shown. After recognition, participants provided similarity 
judgments upon being presented with all target and alternate videos again. To check that the expected typological linguistic differences were actually observed, participants were asked, after they had completed the judgement task, to view the videos again and to describe all events verbally (except, in the Naming First condition, for those already described). A summary of our tasks and conditions is presented in Table 1.

Prior to this experiment, a pre-test was conducted where different groups of Spanish and English participants provided similarity judgments of the videos in the absence of any previous exposure to them. This was pertinent because our main experiment did not allow us to determine a baseline control for the similarity task, i.e. initial similarity biases in the absence of any potentially influencing context. We thus sought to determine whether there were initial preferences in English or Spanish similarity judgments to better evaluate our results of the main study. Note that a corresponding pre-test was not necessary in recognition memory because prior exposure must occur in order to test recognition, and the Free Encoding condition thus constitutes a standard baseline.

\subsection{Specific predictions}

The linguistic differences between English and Spanish discussed earlier allow us to formulate specific predictions about the effect of language on recognition and similarity judgment under different encoding conditions. Predictions can be made for the universal approach and the contrasting language-based views. All predictions assume a linguistic difference between English and Spanish. These predictions are summarized in Table 2. The predictions are not for absolute levels of attention to path or manner, but rather for the pattern of response of one language group relative to the other, because differences between languages in any one encoding condition can be due to between-group differences independent of the manipulations of the study.

\section{Strong Language-based hypothesis}

Because the Strong Language-based view holds that habitual thought patterns influenced by language are stable and acquired during language learning (Lucy, 1993), it predicts that both memory and similarity judgments should reflect language-specific characteristics, regardless of whether the encoding of the events was verbal or non-verbal. Specifically, because Spanish speakers should pay less attention to manner of motion than

Table 1

Summary of tasks in the order given to participants and encoding conditions ${ }^{\mathrm{a}}$

\begin{tabular}{ll}
\hline Phase & Tasks \\
\hline 1. & Encoding of targets: \\
& 1.a. Verbal Encoding: Naming First condition \\
& 1.b. Non-Verbal Encoding: Free Encoding condition/Shadow condition \\
2. & Old/new recognition of targets, including same-manner and same-path alternates \\
3. & Similarity judgments of same-manner vs. same-path alternates relative to targets \\
4. & Verbal descriptions of targets and alternates (or just alternates in the Naming First condition)
\end{tabular}

\footnotetext{
${ }^{\text {a }}$ Different groups participated in each encoding condition. After encoding, tasks 2 to 4 were performed by all groups.
} 
English speakers do, this view predicts for all conditions that (a) in recognition memory, Spanish speakers should be more likely than English speakers to incorrectly identify as old - i.e. false alarm to - events that vary from the target in manner, and (b) in similarity judgments, Spanish speakers should be more likely to use shared path as a basis for judging similarity than English speakers.

\section{Weak Language-based hypothesis}

This hypothesis argues that the on-line processes of language production and interpretation are influenced by linguistic patterns (Slobin, 1996a,b), so that language use can affect perception or conceptualization of the events being referred to. Because manner expression is optional and less codable in Spanish, language use does not necessarily compel speakers to attend to this dimension. This suggests that speakers will pay attention to aspects of events that are made salient by their particular descriptions only after linguistic encoding of visual events. Thus, memory and similarity perception should be affected as specified for the strong hypothesis, but there must be a different pattern of response across conditions: in Spanish, verbal encoding should result in different memory performance and similarity perception (less attention to manner) as compared to the nonverbal conditions, while in English, verbal and non-verbal encoding conditions should be similar because manner and path are both encoded.

\section{Language-as-Strategy hypothesis}

This hypothesis, suggested by the results of Kay and Kempton (1984) and by consideration of the differences between recognition and similarity judgments, claims that people might appeal to certain properties made available in the context in order to reach a decision that would be difficult to solve on other grounds. Note that in the similarity task, participants must make a judgment among items that, in most respects, are very similar to one another. Because no objective standard of similarity exists (Goodman, 1955), judgments of similarity require the intervention of some conscious or unconscious criterion to perform the decision. Such a criterion can be based on contextual features, such as those aspects of the videos highlighted by their descriptions (manner or path dimensions). This contrasts with recognition memory, which is mediated by automatic retrieval

Table 2

Summary of predictions made by each hypothesis ${ }^{\mathrm{a}}$

\begin{tabular}{|c|c|c|c|c|}
\hline \multirow[t]{2}{*}{ Hypotheses } & \multicolumn{2}{|c|}{ Verbal encoding } & \multicolumn{2}{|c|}{ Non-verbal encoding } \\
\hline & Recognition & Similarity & Recognition & Similarity \\
\hline Strong Language-based & Yes & Yes & Yes & Yes \\
\hline Weak Language-based & Yes & Yes & No & No \\
\hline Language-as-Strategy & No & Yes & No & No \\
\hline Universal & No & No & No & No \\
\hline
\end{tabular}

\footnotetext{
a The word yes indicates that the corresponding hypothesis predicts a language effect in the corresponding task and condition.
} 
processes and does have an objective answer (old or new) independent of the context of the task. Consequently, speakers may be more inclined to appeal to language-dependent regularities in similarity judgments than in recognition memory. The Language-as-Strategy hypothesis therefore predicts that (a) in contrast to the Weak Language view, Spanish participants will not differ in recognition memory, and (b) they may show a language effect in their similarity judgments after linguistic encoding, but not after non-linguistic encoding. English speakers, on the other hand, are not expected to differ in any way because regularities guided by their linguistic descriptions during encoding would not influence preferential performance for one or the other dimension.

\section{Universal hypothesis}

This hypothesis, consistent with the proposal by Jackendoff (1990), states that English and Spanish share conceptual structures, differing only in lexical and syntactic linguistic representations. This hypothesis predicts that because recognition and similarity are not intrinsically linguistic tasks, English and Spanish speakers should not differ in their performance, at least not in a way consistent with the linguistic differences.

\subsection{Method}

\subsubsection{Participants}

3.2.1.1. Pre-test The participants were 15 native speakers of English, undergraduates at the University of Maryland, and 15 native Spanish speakers living in the US, all graduate students in the Spanish Department at the University of Maryland, and native from a variety of Spanish-speaking regions. The English fluency of the Spanish speakers varied as a function of the time they had spent in the US, which was between a few months and 5 years.

3.2.1.2. Main study The participants were 47 native speakers of Spanish, all students at Comahue National University, Neuquén, Argentina, and 46 native speakers of English, all students at Brown University in the US. Of these, 16 English and 15 Spanish speakers participated in the Naming First condition, 15 each in the Free Encoding condition, and 16 each in the Shadow condition. Two of the Spanish speakers did not complete the description task for reasons unrelated to the experiment. One of the English speakers consistently pressed the wrong keys during recognition, so his data were omitted from analysis. All Argentineans exclusively used Spanish in their daily activities, although they all had had some training in English. (One of the Argentinean students was fluent in French.) None considered himself or herself fluent in English. All English speakers used English as their primary language. Two participants considered themselves relatively fluent in Japanese and Spanish, respectively.

\subsubsection{Stimulus materials}

The stimuli consisted of digitized short videotapes, comprising a set of 108 motion events. The actions shown in the videos were chosen to allow a sensitive comparison of the linguistic differences in English and Spanish and an evaluation of the relation between 
these differences and performa nce on the non-linguistic tasks. For this reason, only culminated events were included; continuous events or activities such as running and jumping are lexicalized in the same way in English and Spanish.

The videos were organized as a set of 36 triads: 36 targets and 72 alternates, two for each of the target events. ${ }^{4}$ Within a triad, the target video showed a motion event (e.g. an agent walking into a room) while the two alternates portrayed variations in either the manner or the path dimension. In the same-path alternate, the manner of movement was changed while path was kept the same (e.g. the agent striding into the room), while in the same-manner alternate, the direction or path was altered, while manner was held constant (e.g. the agent walking out of the room). A list of the videos is given in Table 4 with the most frequent verbs used in the descriptions.

All videos were filmed in color with a $\mathrm{Hi} 8 \mathrm{~mm}$ video camera in the same room and with the same light conditions (mean duration $=5.03 \mathrm{~s}$ ). To maximize similarity, all actions were performed by the same male individual with the same clothing in a small number of settings. The settings consisted of a background (a white wall) and often an object that played the role of the reference according to which the action of the agent was determined, e.g. a door, a table, a ladder, boxes, etc. Fig. 1 shows frames corresponding to one triad.

\subsubsection{Procedure}

All tasks were performed on a portable G3 Macintosh computer with color screen. Instructions and stimulus presentation were controlled by the participants by clicking a button with the mouse. Participants were told that the purpose of the experiments was to understand people's perception of movies. In the main study, no indication was given that they would later be tested for memory. All instructions were presented to participants in their native language. Instructions were translated into Spanish by the first author (a native speaker of Argentinean Spanish).

3.2.3.1. Pre-test To test whether English and Spanish speakers had initial biases in their evaluation of similarity in the absence of any previous exposure to the videos (establishing a baseline), similarity judgments were collected for all 36 triads. On each trial, the target video was presented first with the label movie 1. After this movie was over, it disappeared from the screen and the same-path and same-manner alternates corresponding to it were shown in sequence with the labels movie 2 and movie 3. These movies stayed side by side on the screen after they were played. Participants had to select the movie that, in their opinion, was more similar to movie 1 by pressing that movie's number on the keyboard. (The instruction was to tell whether movie 2 or movie 3 is more similar to movie 1.) Participants could replay the alternates as many times as they wanted. The order of the initial presentation of the alternates as well as the order of the triads was randomized. A practice session preceded the task to familiarize participants with the procedure.

\footnotetext{
${ }^{4}$ We thank Dan Slobin for providing us with an exhaustive lexicon of English and Spanish motion verbs that was our starting point to develop our stimuli.
} 

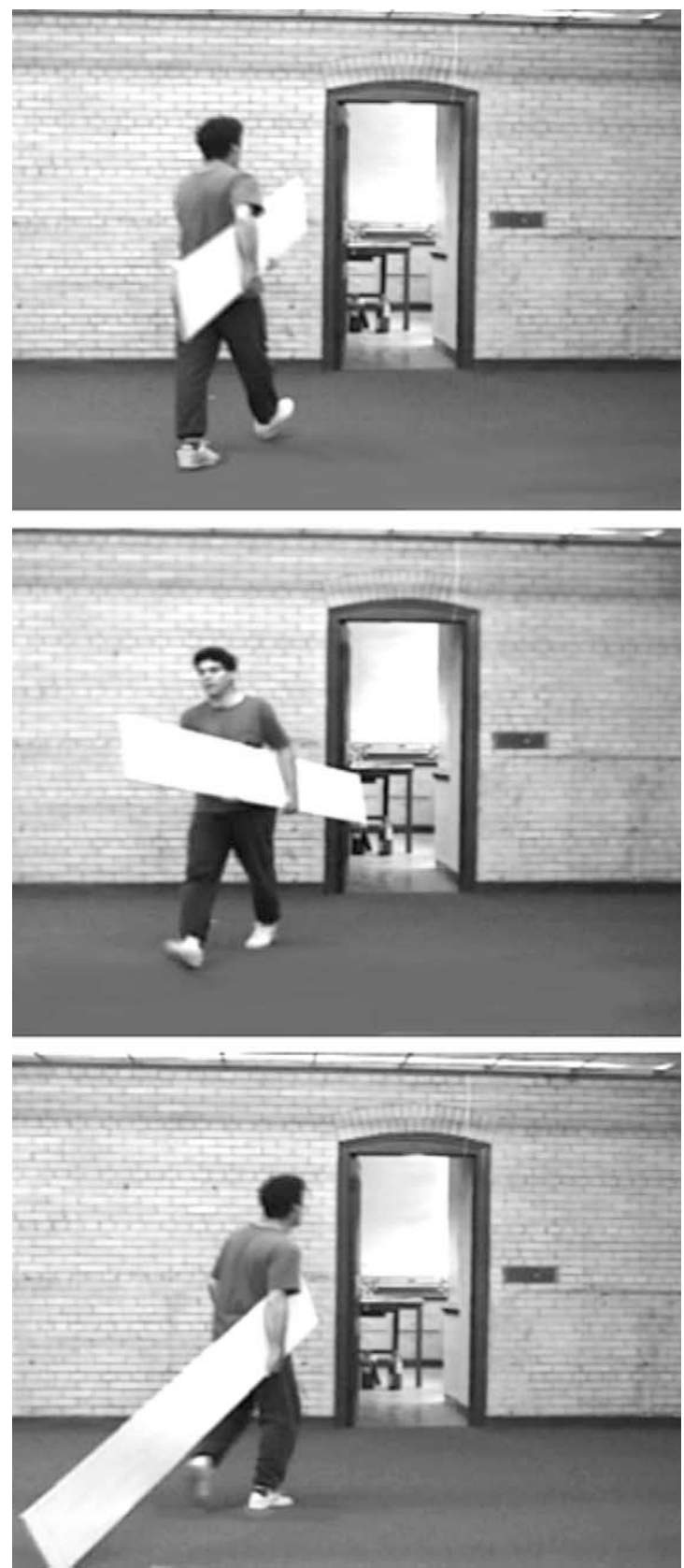

Fig. 1. Triad example. Upper panel: the agent carries the board into the room. Central panel: the agent carries the board out of the room. Lower panel: the agent drags the board into the room. 


\subsubsection{Main study}

Encoding Participants first studied the 36 target videos played on the computer screen. In the Naming First condition, participants were instructed to describe the target videos seen on the screen. They were asked to use a single verb phrase that referred to the event shown as a whole, rather than using several verbs indicating different small actions. ${ }^{5}$ Before recording participants' descriptions, four examples were provided that suggested the general form of the desired descriptions. After each example clip finished, a window appeared asking What happens in the video? (Qué ocurre en el video?) and provided an illustrative answer. Since in Spanish manner adverbs are optional, participants were told that parentheses indicated optional forms, and adverbs appeared in parentheses in the examples. In two cases, the example also contained a comment on the form of the descriptions. Three of the examples were:

1. What happens in the clip? He walks into the room.

2. What happens in the clip? He rolls the can into the box. Do NOT name all actions as in: "he rolls the can then he puts it in the box."

3. What happens in the clip? He crawls in front of the table. ${ }^{6}$

The examples were followed by these instructions:

Remember, a short phrase should describe what happens in the movie as a single event.

Do not describe component actions as in "he first walks and then stops" or as in "he opens the door then he closes it behind him". Rather, you should say "he walks up to the center" or "he goes in". Think of a phrase that may be more general but refers to the totality of what happens in the clip, as if you had to tell somebody what happens in

\footnotetext{
${ }^{5}$ English instructions:
}

Next, you will see several clips. Name the event shown in the clip with a single phrase, as exemplified next. Please, note the structure of the answers. Short phrases describe what happens in the movie as a single event.

\section{Spanish instructions:}

A continuación, verás varios videos. Dále un nombre al suceso o acontecimiento que se muestra en el video con una sola frase verbal corta, como se ejemplifica a continuación. Por favor, prestá atención a la forma de los ejemplos. Una frase corta describe lo que ocurre en el video en su totalidad, como un acontecimiento único. En los ejemplos, los paréntesis indican que esa parte del relato de lo que sucede es opcional.

${ }^{6}$ Spanish examples:

1. Qué ocurre en el video?: (la persona) entra a la habitación (caminando).

2. Qué ocurre en el video?: (la persona) mete la lata en la caja (rodándola). Fijáte: no tenés que indicar cada acción particular, por ejemplo, 'hace rodar la lata y después la mete en la caja'.

3. Qué ocurre en el video?: (la persona) cruza (gateando) por delante de la mesa.

Note: some verb forms in the instructions are only found in Argentinean Spanish, where the second person singular is vos, not tú. 
it. This may be hard to do for some clips. It requires you to take a more general perspective. $^{7}$

During the task, a window asking "What happens in the clip?" appeared after each clip prompting an answer. Participants typed in their descriptions and clicked a button to move on.

In the Free Encoding condition, participants were simply instructed to watch the target videos. Videos were played on the computer screen one after the other until the end of the study set. Finally, in the Shadow condition, participants were asked to repeat nonsense syllables played on the computer speaker while they watched the target videos. The syllables were generated using built-in Apple Macintosh speech synthesis software at $44.1 \mathrm{kHz}$. The nonsense syllables were compatible with both English and Spanish phonology. Consonants and vowels that are similar in both English and Spanish were chosen so that all speakers would be able to reproduce them correctly. The syllables were played as a sequence of three syllables (about one per second) with a short pause between them. After each sequence, a longer pause indicated to the participants that they should repeat them. None of the sequences were words in either language, although some of the syllables, if taken in isolation, were (e.g. to, do, in English, and $l a, l o$, in Spanish). Some examples of these sets of syllables are (written in English phonetic-like orthography): bla-pee-ta, gaplee-ta, lee-pla-chou, da-ka-tee, lo-pla-lou, and koo-lee-moo. The sequences did not sound like words in either language, and participants were told that the syllables were nonsense sequences.

Distraction In all conditions, encoding was followed by a retention interval to make recognition harder and increase errors. This phase consisted of solving three probability problems unrelated to the current study and lasted between 10 and $20 \mathrm{~min}$.

Recognition After distraction, a new set of instructions was shown to participants in all conditions. Participants were instructed to respond to each video as quickly as they could by indicating whether or not they had seen the video by pressing a key on the keyboard. All 108 clips (targets and alternates) were tested in random order, 36 of which had been seen during encoding.

Similarity judgments Similarity judgments were collected for all 36 triads after recognition in all conditions. The procedure and instructions were the same as in the pre-test.

\footnotetext{
${ }^{7}$ Spanish instructions:

Acordáte, una sola frase corta debe describir todo lo que ocurre en el video como un solo acontecimiento. No describas las acciones que componen el video, por ejemplo, "primero camina y después se detiene", o "abre la puerta y después la cierra". En su lugar, tenés que decir algo asi como "camina hasta el centro" (o "se para en el centro") o "entra en la habitación".

Buscá una frase que refiera a la totalidad de lo que ocurre en el video, aunque sea una frase mas genérica, como si tuvieras que contarle a alguien qué es lo que sucede en el video.

A veces puede ser difícil encontrar la frase apropiada. Tenés que ver el video desde una perspectiva más general. También, puede haber varias frases alternativas que describan el mismo acontecimiento. En ese caso, elegí la mas natural.
} 
Descriptions In this section, participants in the Shadow and Free Encoding conditions saw all 108 videos again and were asked to provide a description for each video. Naming instructions were identical to those for the Naming First condition above. In the Naming First condition, participants described the 72 videos (the sets of alternates) that they had not described in the first part of the experiment.

\section{Results}

The results are described in five sections. In the first section, we report the results of the pre-test that serves as a baseline test of similarity preferences in both English and Spanish. In the remaining sections, we describe the results of our main study. In order to validate our premise that the languages describe the actions differently, we report the linguistic differences between the two languages. Then we compare the memory performance and similarity judgments of English and Spanish speakers. Finally, to evaluate the participants' criteria in the similarity task, we examine the relation between linguistic descriptions and similarity choices.

\subsection{Pre-test}

To test whether English and Spanish speakers had initial biases in perception of the similarity of our items, we measured their similarity choices without any previous exposure to the videos. Note that the Strong Language-based view would predict an overall language effect in this test, over and beyond any general non-linguistic biases due to perceptual salience of one dimension or the other, because such an effect should not be dependent on contextual influences. Under this view, Spanish participants should make more same-path choices than English speakers. The mean proportion of same-path choices in English was 0.61, while in Spanish it was 0.51. An unpaired $t$-test with the mean proportions of same-path choices as a dependent variable showed that the difference was not significant across subjects $(t(30)<1, P=$ NS, Spanish SE: 0.05, English SE: $0.07)$, although it was significant across items $(t(70)>2, P<0.01$, Spanish SE: 0.04 , English SE: 0.02), because variance among participants was higher than among items. These results indicate that (a) there is no strong a priori bias toward one dimension or the other for either group of participants (there is no reliable evidence for a difference between the two groups), and (b) there is no evidence for a language-based bias toward more path choices for Spanish speakers. ${ }^{8}$

\subsection{Main study: comparison of linguistic differences}

We now report results from the main experiment. The linguistic descriptions were analyzed separately for each language in order to verify the predicted linguistic differences and to establish whether the verbs that we used when developing the stimuli were, in fact, used by participants to describe the stimuli. First, we determined the dominant or most

\footnotetext{
${ }^{8}$ Note that even if one interprets the English results as an initial bias, this would not be consistent with any language-based expectation.
} 
Table 3

Examples of naming distributions in English and Spanish ${ }^{\mathrm{a}}$

\begin{tabular}{|c|c|c|c|}
\hline & Target & Same-manner alternate & Same-path alternate \\
\hline $\begin{array}{l}\text { English } \\
\text { Spanish }\end{array}$ & $\begin{array}{l}\text { run in } \\
\text { entra (corriendo) }\end{array}$ & $\begin{array}{l}\text { run out } \\
\text { sale (corriendo) }\end{array}$ & $\begin{array}{l}\text { walk in } \\
\text { entra (caminando) }\end{array}$ \\
\hline
\end{tabular}

${ }^{a}$ Underlined material in each row indicates the same choice of main verb.

frequent verb given to each video across all conditions. In English, the target event was typically named with the same verb as the same-manner alternate. In contrast, Spanish speakers named the target event with the same verb as the same-path alternate. This pattern is exemplified in Table 3, where underlined phrases indicate the assignment of same verb within a language. As expected, $92 \%$ of the triads followed this linguistic pattern in each language. Table 4 shows the dominant verbs selected for each member of the 36 triads in each language. For illustration, material in parentheses exemplifies further components of the verb phrase, although Spanish adverbs indicating the manner of the event are not shown.

Second, we classified each main verb as manner or path or some other type. The classification closely agrees with the criteria and examples discussed by Slobin (1996a, 1998), Talmy (1985), and Naigles, Eisenberg, Kako, Highter, and McGraw (1998). ${ }^{9}$ The results were similar to those of Naigles et al. (1998). On average across subjects, the proportion of verbs that were manner verbs in English was 0.86, and the proportion of path expression with these verbs (by particles or prepositional phrases) was the same. This is because for our set of events, verb + particle was required. For example, for an entering event, it was not appropriate to simply report it as he walks. The correct descriptions are he walks in or he walks into the room. In Spanish, the proportion of verbs that were path verbs was 0.80 , while the proportion of descriptions that contained manner expressions (via adverbs or verbs) was 0.71 . Thus, each language preferred either manner or path verbs in every condition and followed the expected pattern.

Finally, we asked whether English and Spanish differed in the frequency of manner information expressed linguistically. Slobin's studies suggest that due to the lexical constraints of the Spanish language and the optionality of adverbs, Spanish speakers should be less compelled to specify the manner of the action, unless it was required by the context. In contrast, English speakers should not be biased in this way because the preferred pattern of English is manner verb + path particle. Either a manner verb or a manner modifier (adverbs or prepositional phrases) were considered a linguistic expression of manner. The results showed that English speakers expressed manner more often than Spanish speakers. Averaging across conditions, English participants expressed

\footnotetext{
${ }^{9}$ Path verbs indicate the direction of the movement with regard to some landmark or ground object (e.g. enter, exit, introduce, cross (over), pass (by), arrive, etc.) and entail a change of location (Dowty, 1979; Jackendoff, 1990; Levin \& Rappaport Hovav, 1992). Manner verbs specify the pattern of motion (e.g. walk, run, crawl, stomp, march, dance, hop), the rate of the motion (run, jog, hurry, sprint), or the attitude of the agent (stagger, sneak, sashay) (Slobin, 1998; Talmy, 1985).
} 
Table 4

Frequent verbs used to describe event triads in English and Spanish

\begin{tabular}{|c|c|c|c|c|}
\hline Triad no. & Standard & Same-path alternate & Same-manner alternate & Scene object \\
\hline \multirow[t]{2}{*}{1} & walks (up) & jumps (up) & walks (down) & stairs \\
\hline & sube & sube & baja & stairs \\
\hline \multirow[t]{2}{*}{2} & skips (in) & hops (in) & skips (out) & door \\
\hline & entra & entra & sale & door \\
\hline \multirow[t]{2}{*}{3} & limps (across) & stumbles (across) & limps (up to) & frame \\
\hline & pasa & cruza/pasa & detiene/llega & frame \\
\hline \multirow[t]{2}{*}{4} & slides (down) & rolls (down) & slides (up) & table \\
\hline & baja & cae & sube & table \\
\hline \multirow[t]{2}{*}{5} & drags (in) & carries (in) & drags (out) & stool \\
\hline & arrastra/entra & entra & saca & stool \\
\hline \multirow[t]{2}{*}{6} & sneaks (in) & tiptoes (in) & sneaks (out) & door \\
\hline & entra & entra & sale & door \\
\hline \multirow[t]{2}{*}{7} & walks (between) & marches (btwn) & walks (up to) & chairs \\
\hline & pasa & pasa & detiene & chairs \\
\hline \multirow[t]{2}{*}{8} & hops (up) & walks (up) & hops (down) & stairs \\
\hline & sube & sube & baja & stairs \\
\hline \multirow[t]{2}{*}{9} & drags (in) & puts (in) & drags (out) & boxes \\
\hline & mete & mete & saca & boxes \\
\hline \multirow[t]{2}{*}{10} & gets (down) & jumps (down) & gets (out) & table \\
\hline & (se) mete & (se) mete & sale & table \\
\hline \multirow[t]{2}{*}{11} & skips (across) & jogs (across) & skips (up to) & board \\
\hline & pasa & pasa & llega & board \\
\hline \multirow[t]{2}{*}{12} & runs (in) & jogs (in) & runs (out) & door \\
\hline & entra & entra & sale & door \\
\hline \multirow[t]{2}{*}{13} & jumps (into) & steps (into) & jumps (across) & frame \\
\hline & esconde & esconde & pasa & frame \\
\hline \multirow[t]{2}{*}{14} & crawls (down) & slides (down) & crawls (up) & board \\
\hline & baja & baja & sube & board \\
\hline \multirow[t]{2}{*}{15} & walks (behind) & squeezes (bhd) & walks (up to) & table \\
\hline & pasa & pasa & detiene & table \\
\hline \multirow[t]{2}{*}{16} & crawls (into) & hops (into) & crawls (across) & blackboard \\
\hline & esconde & esconde & pasa & blackboard \\
\hline \multirow[t]{2}{*}{17} & sneaks (through) & walks (through) & sneaks (behind) & frame \\
\hline & pasa & pasa & esconde & frame \\
\hline \multirow[t]{2}{*}{18} & walks (up) & jogs (up) & walks (down) & stairs \\
\hline & sube & sube & baja & stairs \\
\hline \multirow[t]{2}{*}{19} & climbs (down) & jumps (down) & climbs (up) & table \\
\hline & (se) baja & (se) baja & sube & table \\
\hline \multirow[t]{2}{*}{20} & crawls (under) & rolls (under) & crawls (across) & ladder \\
\hline & llega/camina & rueda & pasa & ladder \\
\hline \multirow[t]{2}{*}{21} & walks (in) & walks (in) & walks (out) & door \\
\hline & entra & entra & sale & door \\
\hline \multirow[t]{2}{*}{22} & kicks (together) & moves (together) & kicks (apart) & ball box \\
\hline & acerca & junta/acerca & separa & ball/box \\
\hline 23 & staggers (in) & limps (in) & stumbles (out) & door \\
\hline & entra & entra & sale & door \\
\hline 24 & walks (over) & hops (over) & walks (up to) & board \\
\hline & pasa & pasa & detiene & board \\
\hline
\end{tabular}


Table 4 (continued)

\begin{tabular}{|c|c|c|c|c|}
\hline Triad no. & Standard & Same-path alternate & Same-manner alternate & Scene object \\
\hline \multirow[t]{2}{*}{25} & carries (in) & drags (in) & carries (in) & stool \\
\hline & entra & entra & saca & stool \\
\hline \multirow[t]{2}{*}{26} & kicks (in) & rolls (in) & kicks rolls (out) & ball box \\
\hline & mete & mete & saca & ball box \\
\hline \multirow[t]{2}{*}{27} & runs (between) & hops (between) & runs (up to) & stools \\
\hline & pasa & pasa & corre & stools \\
\hline \multirow[t]{2}{*}{28} & dances (over) & waltzes (over) & dances (up to) & board \\
\hline & pasa & pasa & baila & board \\
\hline \multirow[t]{2}{*}{29} & moves/slides & moves & drags/moves & boxes \\
\hline & acerca & acerca & separa & boxes \\
\hline \multirow[t]{2}{*}{30} & walks (in) & marches (in) & walks (out) & door \\
\hline & entra & entra & sale & door \\
\hline \multirow[t]{2}{*}{31} & walks (out) & trips & walks (in) & door \\
\hline & sale & tropieza & entra & door \\
\hline \multirow[t]{2}{*}{32} & crawls (through) & crawls (through) & crawls (up to) & frame \\
\hline & pasa & pasa & camina & frame \\
\hline \multirow[t]{2}{*}{33} & rolls (in) & puts (in) & rolls (out) & can box \\
\hline & mete & mete & saca & can box \\
\hline \multirow[t]{2}{*}{34} & climbs (up) & jumps (up) & climbs (down) & ladder \\
\hline & sube & sube & baja & ladder \\
\hline \multirow[t]{2}{*}{35} & walks (through) & jogs (through) & walks (up to) & frame \\
\hline & pasa & pasa & camina & frame \\
\hline \multirow[t]{2}{*}{36} & dances (across) & dances (across) & dances (up to) & room \\
\hline & pasa & pasa & baila & room \\
\hline
\end{tabular}

manner in $86.16 \%$ of the items, while Spanish participants did so in $71.33 \%$ of them. An ANOVA on the proportion of cases where manner was specified revealed a significant main effect of language $(F(1,86)=78.72$, MSE $=0.51, P<0.0001)$, a significant effect of condition $(F(2,86)=5.35, \mathrm{MSE}=0.03, P<0.01)$ and an interaction of language and condition $(F(2,86)=4.55, \mathrm{MSE}=0.03, P<0.01)$. The analysis across items yielded an identical pattern (language effect: $F(1,107)=60, \quad P<0.01$; condition effect: $F(2,214)=223.6, P<0.01$; interaction: $F(2,214)=45.4, P<0.01)$. The interaction occurred because manner was expressed less often in Spanish relative to English in all conditions, and the Spanish conditions differed among themselves. The Spanish mean proportion of manner expression in the Naming First condition was 0.64 vs. 0.86 in English, in the Free Encoding condition, the proportions were 0.76 in Spanish vs. 0.86 in English, and in the Shadow condition, the proportions were 0.73 in Spanish vs. 0.86 in English. These results were shown by post-hoc comparisons: in English, there was no difference across conditions, while in Spanish, most conditions differed, with the Naming First condition showing less manner expression: Free Encoding vs. Naming First (subject analysis: $P<0.01$; item analysis: $P<0.001$ ); Shadow vs. Naming First (subject analysis: $P=0.01$; item analysis: $P<0.001)$. The two languages significantly differed across all conditions (subject analysis: $P<0.0001$; item analysis: $P<0.001$ ). These linguistic differences will be critical in the interpretation of our results. 
Overall, these results indicate that (a) each language has a preferred pattern of describing the actions consistent with the Talmy (1985) typology, (b) there is a preferred type of verb as well as verb phrase for each language (manner verbs + particle for English and path verbs + optional manner adverb for Spanish), and (c) Spanish speakers express manner information less often than English speakers, as found by Slobin (1996a,b). This was particularly so in the Naming First condition, despite the salience of the manner element in all videos.

\subsection{Main study: recognition memory performance}

Before considering the specific predictions regarding false alarms to alternate types, we provide an overview of memory performance. We report both overall hit rates (proportion of "yes" answers to targets shown in Fig. 2) and false alarms (probability of incorrect "yes" answer). In the analysis of hit rates across subjects, there were effects of language and condition. A $2 \times 3$ ANOVA comparing languages and encoding conditions yielded a main effect of language $(F(2,86)=9.37, \mathrm{MSE}=0.12, P<0.001)$ and condition $(F(2,86)=29.16, \mathrm{MSE}=0.37, P<0.001)$ with a significant interaction between the two $(F(2,86)=5.89$, MSE $=0.07, P<0.001)$. Analysis across items yielded an identical pattern of results (language effect: $F(1,35)=21.9, P<0.0001$; condition effect: $F(2,70)=39.3, P<0.0001$; interaction: $F(2,70)=21, P<0.0001)$. Post-hoc Fisher tests revealed that the effect of language was due entirely to the Shadow condition, with Spanish speakers finding the Shadow condition harder (English mean: 0.67 vs. Spanish: $0.49 ; P<0.001$ both across subjects and items). Within each language, the condition effect indicates that the nature of encoding made a difference, with the Shadow condition consistently the most difficult in both languages. In English, the Shadow condition differed significantly from the Free Encoding condition (subject analysis: $P<0.04$;

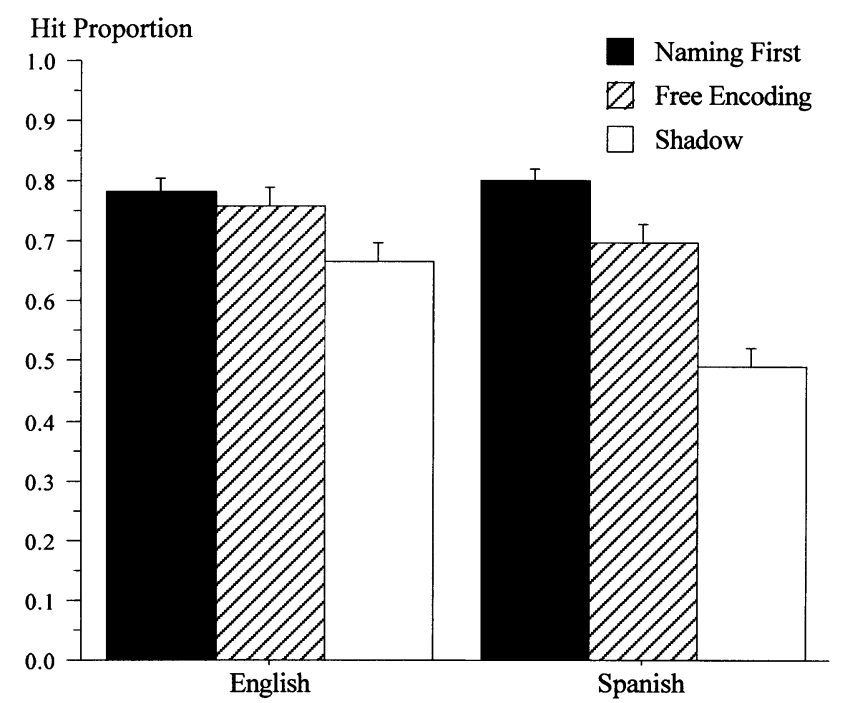

Fig. 2. Proportion of hits in memory performance as a function of language and encoding conditions. 
Table 5

Mean number of false alarms as a function of item type and encoding condition

\begin{tabular}{llll}
\hline & Free Encoding & Naming First & Shadow \\
\hline English & & & \\
Same-path item & 7.13 & 6.79 & 12.75 \\
Same-manner item & 7.73 & 4.79 & 13.38 \\
Spanish & & & \\
Same-path item & 9.00 & 6.94 & 13.25 \\
Same-manner item & 9.00 & 5.38 & 12.62 \\
\hline
\end{tabular}

items: $P<0.01$ ) and the Naming First condition (subject: $P<0.01$; items: $P<0.001$ ). In Spanish, all comparisons were significant (Free Encoding vs. Naming First: $P<0.01$; Free Encoding vs. Shadow and Naming First vs. Shadow: $P<0.0001$ in all analyses).

In the analysis of false alarms, the comparison across languages was not significant. Only a main effect of condition was observed in both across subject and item analyses (subjects: $\quad F(2,86)=37.81, \quad \mathrm{MSE}=0.31, \quad P<0.001 ; \quad$ items: $\quad F(2,70)=98.54$, $P<0.0001$ ). This indicates that (a) differences in hit rates between languages in the Shadow condition were not a result of a greater tendency of Spanish speakers to answer "no", and (b) the two languages did not differ in rates of false alarms. Post-hoc comparisons showed the exact same pattern of results as the hit rates, i.e. false alarms showed the effect of the encoding conditions, with more marked differences in Spanish. ${ }^{10}$

Overall, these results indicate that (1) the only difference in recognition memory between the two languages is that Spanish speakers were worse in the Shadow condition than English speakers, and (2) memory performance varied as a function of the encoding conditions, i.e. the more difficult the encoding, the less accurate recognition, with more marked differences in Spanish.

\subsubsection{Manner vs. Path differences}

We turn now to the evaluation of the predictions regarding false alarms to one or the other type of alternate. The prediction of the Strong and Weak Language-based hypotheses is that, because Spanish speakers focus on path more than English speakers do, they should incorrectly identify same-path alternates as old more often than English speakers. Table 5 shows the mean number of false alarms for each alternate type in all conditions and languages. A $2 \times 3$ ANOVA comparing across subjects the relative proportion of incorrectly accepting the same-path over the same-manner alternate (false alarms to same-path item/total false alarms) revealed no significant difference between the languages $(F(2,86)=0.78, \quad \mathrm{MSE}=0.01, \mathrm{NS})$, a main effect of condition $(F(2,86)=4.43$, MSE $=0.07, P<0.05)$, and no interaction $(F(2,86)=0.76, \mathrm{MSE}=0.01, \mathrm{NS})$. The same was true for the analysis across items (condition effect: $F(2,54)=3.34$, $P=0.04)$. Multiple post-hoc comparisons among conditions yielded only one significant

\footnotetext{
${ }^{10}$ These results were further supported by several complementary analyses. We compared correct response rates (hits plus correct rejections) and $d^{\prime}$ scores (normalized differences between hit and false alarm rates). All analyses revealed the same pattern of results.
} 
difference, that for English between the Free Encoding and Naming First conditions (subjects: $P=0.02$; items: $P=0.08$ ). However, there were too few false alarms in this condition (on average, six out of 72 possible) to draw any conclusion. Overall, the prediction of the language-based hypotheses (Strong or Weak) does not hold in recognition memory.

\subsection{Main study: similarity judgments}

Before testing the language-based hypotheses, we compared the results of the similarity task to the baseline established by the pre-test. We sought to evaluate whether participation in an encoding phase and recognition task (i.e. becoming acquainted with the stimulus set prior to similarity judgments) biased participants' choices in our main experiment. We found that participants in the Free Encoding condition behaved as they did in the pre-test $(t(15)<1)$ in both languages and all analyses, thus supporting our initial expectation that the Free Encoding condition could be taken as a baseline control in our main experiment. The remaining conditions differed from the pre-test baseline in the same way that they differed from the Free Encoding condition. We thus take the Free Encoding as our baseline and report our results relative to it.

In our comparison of the proportion of same-path choices for all three main conditions, we confirmed the language-based expectation that English and Spanish differed in their similarity judgments, with Spanish speakers making more same-path choices in the Naming First condition. The results are shown in Fig. 3. A $2 \times 3$ ANOVA across subjects revealed a main effect of encoding condition $(F(2,87)=11.14, \mathrm{MSE}=0.55, P<0.001)$, no overall language effect $(F(1,87)<1)$ and a significant interaction $(F(2,87)=6.24$, MSE $=0.31, P<0.01)$. An identical pattern was obtained across items (language effect: $F(1,35)=0.09$; condition effect: $F(2,70)=127.4, P<0.0001$; interaction: $F(2,70)=$

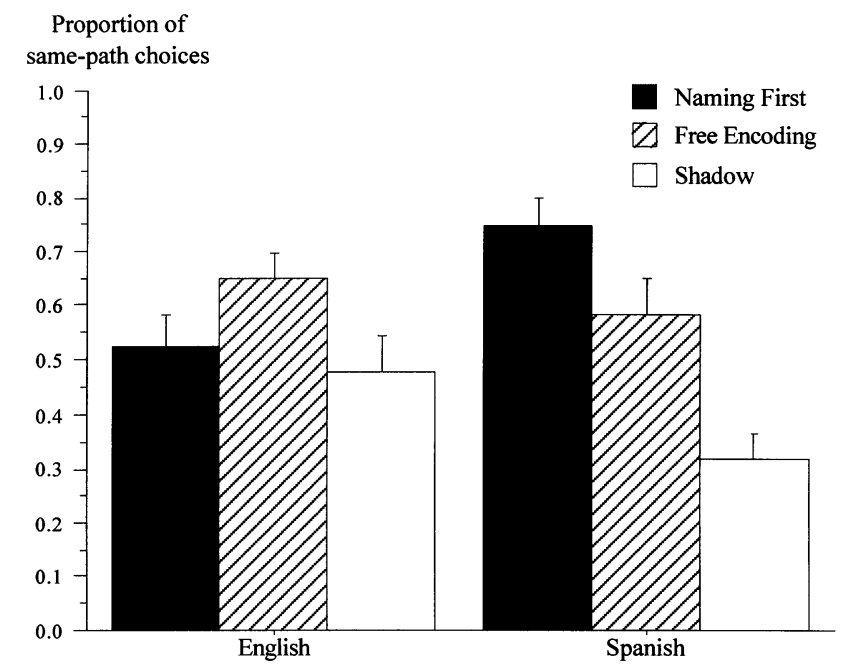

Fig. 3. Proportion of same-path similarity choices in the similarity task as a function of language and encoding conditions. 
79.6, $P<0.0001)$. The significant interaction indicates that the encoding previous to the similarity task as well as linguistic differences influenced similarity judgments. The linguistic influence was further confirmed by planned comparisons across languages, which revealed that Spanish speakers were more likely to select same-path alternates than English speakers in the Naming First condition $(0.75$ vs. $0.53, P=0.006$ and $P=$ 0.0001 across subjects and items, respectively), but not in the other conditions. This pattern of results is consistent with the predictions of the Weak Language-based and the Language-as-Strategy hypotheses.

Planned comparisons across conditions within each language also revealed differences that depended on previous encoding. Taking the Free Encoding as our baseline condition, the Naming First condition produced an increase in preference for same-path alternates in Spanish (subjects: $P=0.04$; items: $P=0.0001$ ) but not in English, as expected on the basis of linguistic characteristics. Also, the Spanish Shadow condition showed a decrease in same-path choices relative to the baseline (subjects: $P=0.002$; items: $P=0.0001$ ), with same-manner alternates preferred. In English, same-path choices also decreased in the Shadow condition relative to the baseline Free Encoding condition (subjects: $P=0.038$; items: $P=0.001$ ), although less markedly than in Spanish. Finally, there was no significant difference in English between the Free Encoding and Naming First conditions in the analysis across subjects, indicating that the mean difference does not generalize to new subjects, but there was one in the analysis across items $(P=0.01)$.

These results indicate that the nature of the encoding had an effect on similarity judgments within each language. Shadowing led to fewer same-path choices in both languages relative to the baseline. However, only Spanish showed an increase in preference for samepath alternates in the Naming First condition relative to the baseline. This pattern of results is consistent with the idea that greater weight was given to the manner or path dimension during similarity judgments when that dimension was initially brought to attention through the previous encoding task. For Spanish, encoding in the Naming First condition involved explicit linguistic descriptions that emphasized path over manner, and the path dimension was more heavily relied on in similarity judgments. In contrast, for both languages, when encoding was combined with a shadowing task, the decrease in same-path preferences may be due to shallow processing during encoding, as suggested by the poor memory performance in the Shadow condition relative to Free Encoding. Note that to perceive the manner of motion, a few consecutive video frames displaying the most naturally salient agent are sufficient (Todd, 1983). In contrast, to perceive the path, a more complete encoding of the temporal development of the event as well as information extrinsic to the agent is necessary (Bingham, 1985; Bingham, Schmidt, \& Rosemblum, 1995). This suggests that participants in the Shadow condition were less likely to perceive path information because they had to switch their attention between the secondary auditory/ motor task and the visual encoding of the videos. Thus, perception of manner was relatively better than perception of path. This was particularly so in Spanish, where there was worse encoding, as indicated by their memory performance. In the Naming First condition, however, when encoding was combined with descriptions, participants were able to encode the full temporal development of the videos along with the properties highlighted by their descriptions.

Overall, these results are consistent with the Language-as-Strategy hypothesis. They are 
also partially consistent with the Weak Language-based hypothesis in that only after linguistic encoding were Spanish speakers more likely to select the same-path item, compared to other conditions or to English speakers. The language effect occurred only when language was relevant during initial encoding.

\subsection{Spanish manner and path choices as a function of linguistic descriptions}

The relation between linguistic descriptions and similarity choices can shed light on the exact nature of the language effect: did the similarity choice for each event depend on each event's individual description at encoding? Or did it depend on whether path is more often described than manner across all the events? These options imply different views on the relation of descriptions to similarity. On the one hand, if, as proposed by Slobin, language use affects representations of events, and if naming itself entails attention to those aspects named, then the dimension(s) described for an individual event should be those focused on during similarity choices. Under this view, the features of an event made salient during encoding would shape the perception of it upon retrieving its initially encoded representation. We will call this view the event-specific alternative. On the other hand, the second option implies a view of the linguistic effect that does not require the retrieval of an eventspecific memory representation. The overall weight of one dimension over the other in the descriptions would bias participants' performance generally, regardless of the individual description given to a particular event (an event-general alternative). This view assumes only that participants have abstracted the importance of the manner or path features from the encoding task.

We can test the predictions of these options by looking at similarity choices in Spanish, rather than English, because only Spanish shows results consistent with differential attention to visual aspects on the basis of linguistic properties. We can determine which similarity choices Spanish speakers made when they mentioned either only path or both path and manner in their descriptions. Because describing a dimension implies paying attention to it during encoding, the event-specific alternative predicts that speakers should choose actions sharing path as more similar than those sharing manner only for those events where manner was not encoded. For those events where both manner and path were described, it predicts no particular preference. In contrast, the event-general alternative predicts that because of the overall dominance of path expression over manner during linguistic encoding for Spanish speakers, participants should prefer same-path choices regardless of the particular description of each event.

To test these predictions, we selected all similarity responses to targets that had been described using manner and path information together vs. targets that were described with path information alone. The proportions of same-path similarity choices in these sets are shown in Table 6 for each encoding condition in Spanish. The results were entirely parallel to the pattern of the main similarity analysis for both sets of descriptions. A $2 \times 3$ ANOVA with the proportion of same-path choice as a dependent variable, and encoding conditions and verbal description (whether manner plus path or path alone) as factors revealed a main effect of encoding condition $(F(86,2)=22.69, P \leq 0.01)$ and no effect of type of verbal description. The analysis across items yielded an identical pattern.

We also compared similarity judgements corresponding to path vs. manner verbs used 
Table 6

Mean proportion of choosing the same-path item in the Spanish similarity task for target items that were described with either path information alone or both manner and path information

\begin{tabular}{llll}
\hline Spanish descriptions & Free Encoding & Naming First & Shadow \\
\hline Path expression & 0.60 & 0.77 & 0.38 \\
Manner and Path expression & 0.57 & 0.70 & 0.30 \\
\hline
\end{tabular}

in the encoding phase to check whether the verb alone (as opposed to the entire description) was responsible for the language effect on similarity. The analysis showed the same pattern of results as above in both types of analysis. Although there were relatively few cases of manner verbs in the Spanish descriptions, the mean proportions of same-path choices for Naming First were similar (0.78 vs. 0.72) for both manner and path verbs.

These analyses indicate that events that were named with a manner verb or included manner information were associated with same-path choices to the same extent as events named with path verbs alone. This outcome suggests a conscious or unconscious selection strategy in similarity judgment that focuses on the path dimension as a consequence of the overall weight of one dimension over the other, not as a consequence of how individual events were encoded. Spanish speakers were biased by the dimension made salient by their descriptions, rather than directly retrieving their own linguistic classification of each event.

\section{Discussion}

\subsection{Summary of results}

Our results show, first, that our videos elicited different verb phrase patterns in each language as predicted by the standard linguistic typology. In particular, (a) Spanish speakers tended to assign the same verb to actions that share path, while English speakers did so for actions that share manner, (b) Spanish speakers overwhelmingly used more path verbs than English speakers, and (c) in Spanish, manner of motion was indicated less often than in English, and also less often in the Naming First condition than in other conditions.

Second, our analysis of the recognition memory data indicated that within each language, performance was highest in the Naming First condition and lowest in the Shadow condition, while performance in the Free Encoding condition was in between. English speakers performed better than Spanish speakers in the Shadow condition. However, the probability of incorrectly identifying either same-path or same-manner alternates did not differ across languages, i.e. there was no evidence that language was mediating or influencing recognition performance.

Third, our analysis of the similarity data indicated several within-language differences, despite the fact that perceptually, the Spanish and English tasks were exactly alike. In Spanish, all conditions differed in that same-path choices decreased in the Shadow condition and increased in the Naming First condition relative to the Free Encoding baseline. English speakers showed a similar but less pronounced decrease in the Shadow condition, 
but critically, no increase was observed in the Naming First condition relative to the Free Encoding. We have attributed these effects to characteristics of the encoding conditions that emphasized specific properties of the stimuli, later focused on in the similarity task. Of these effects, the only one that can be attributed to linguistic differences was in the Naming First condition, the only condition that required linguistic encoding of the events. In this condition, the higher probability of selecting the same-path alternate by Spanish speakers was consistent with their greater use of path to describe the events.

Finally, to understand the nature of the linguistic influence on the similarity task, we analyzed the relation between similarity judgments and linguistic descriptions in Spanish. The analysis revealed that events described with path verbs alone were not more likely to be associated with same-path choices than events described with manner verbs, or with path and manner expressions. This suggests that the path preference did not arise from recovering the specific linguistic encoding of an event, but rather, from the overall weight or salience of the path dimension in the linguistic descriptions.

\subsection{Evaluating the hypotheses}

Recall from Table 2 that the Strong Language-based view predicted a language effect on both memory performance and similarity judgment after both linguistic and non-linguistic encoding, while the Weak Language-based view predicted a language effect on both tasks but only after linguistic encoding. The absence of a language effect on recognition memory is inconsistent with both of these hypotheses. The hypothesis that predicted an effect only in the similarity task was the Language-as-Strategy hypothesis. As predicted, English and Spanish speakers' similarity judgments in the Naming First condition were biased by their prior use of language, but only after linguistic encoding. Spanish speakers were more likely to select the same-path alternate, while English speakers showed no preference. This was consistent with the pattern of descriptions observed in each language. Further analysis of the similarity choices suggested that the effect of language was strategic in that the dimension of the motion event more attended to during descriptions was the one relied on more heavily during similarity judgments. This strategy was not eventspecific but an overall bias.

\subsection{The nature of the linguistic mediation}

Although our data are consistent with the Language-as-Strategy hypothesis, an alternative explanation of the linguistic effect for Spanish speakers that we have not yet considered is that participants might have adopted a purely on-the-spot verb-based strategy. The previous naming in the Naming First condition could have primed the use of names as a decision strategy, independently of properties of the encoding per se. Because stimulus events sharing path frequently have the same verb label in Spanish, in contrast to those sharing manner, speakers could have selected a given event as more similar on the basis of their name similarity (evaluated at the time of the response). We think that this possible explanation of the language effect is highly unlikely. First, note that in both languages, properties of the visual encoding in the Shadow condition resulted in more same-manner preferences relative to the Free Encoding baseline. This suggests that how videos were encoded did affect similarity choices. Second, if there was a purely on-the-spot verb-based 
strategy in Spanish, there would be no apparent reason why English speakers would not have adopted it too. But English similarity choices did not closely follow the pattern of English names; choices favored shared path as much as shared manner. Finally, the relation between descriptions and similarity does not support a purely on-the-spot naming strategy, because Spanish same-path choices were proportionally the same for events described with either path or manner verbs. Thus, we are inclined to conclude that it was a bias created by the original linguistic encoding of the videos, rather than on-the-spot verb-based descriptions, that led to similarity judgments in the Naming First condition.

We are left with a version of the Language-as-Strategy view whereby Spanish speakers selected the same-path alternate because this was the dimension more often attended to during naming (the event-general alternative). To describe the events, English speakers had to attend to the manner of action as well as the agent's location and orientation relative to the ground objects, because both the manner verb and the path particle had to be produced. Consequently, prior encoding of the videos, whether linguistic (Naming First condition) or not (Free Encoding condition), had little effect on what would be attended to during the similarity task. However, Spanish speakers more consistently attended to path features in the Naming First condition, because this element is obligatorily expressed in their descriptions. As Slobin suggests, for Spanish speakers, attending to manner of motion when describing an event is optional and occurs less often than for English speakers. Spanish speakers were either primed by previous descriptions to focus on path, or consciously decided to use this dimension as a selection criterion. As a result, the attention drawn by the linguistic requirements consciously or unconsciously inclined participants to give path features more weight in their similarity choices.

\section{General discussion}

Our results are revealing about the relation between cognitive and linguistic representations. Are conceptual representations universal and relatively independent of linguistic representations? Or are the two types of representation linked with language shaping thought? Our study suggests that both views are partially correct. On one hand, the representations of motion events accessed during recognition memory are not influenced by the linguistic regularities studied here. This is not entirely surprising. Visual representations are presumably richer than ordinary linguistic descriptions. Note that linguistic representation of space and spatial relations across languages is rather coarse (Landau \& Jackendoff, 1993; Talmy, 1985). The same is true for linguistic representations of manner of motion. Despite the large number of lexical items representing different manners of motion in English, a linguistic description cannot be infinitely fine-grained: any sentence representing a motion event can describe several slightly different situations, and is thus likely to underdetermine its referent. Thus, speakers are limited in their ability to use language alone to remember and identify visual events.

On the other hand, our results indicate that some non-verbal tasks such as similarity judgments may be influenced by language. In certain contexts, it may be useful to appeal to features of the linguistic encoding highlighted by the linguistic descriptions, precisely because they are more schematic and suited for the task at hand than detailed visual and 
conceptual representations. This leaves open the possibility that language may provide useful tools for other tasks, such as those involving reasoning and categorization (Sloman, 1996). Language may or may not influence performance depending on the processes, goals, and conditions at hand. Performance in some tasks may reflect non-linguistic representations, while in others, it may be shaped by language.

At the same time, our results also suggest that linguistic labels and non-linguistic event concepts are separate and dissociable. Language biases in the similarity task reflected the constraints imposed by general lexical patterns, not the identity of labels given to specific actions (the on-the-spot verb-based vs. event-generic strategies). This dissociation between naming (or verbal classification) and perception of similarity parallels that found by Malt et al. (1999) in the domain of objects and supports the postulation of different categorization acts, which Malt et al. called naming vs. recognizing. Recognition categories are those drawn from the representation of the similarity among objects. These categories are the ones accessed by our participants in all conditions, rather than those based on verbal classifications.

In a different domain, our results bring some order to data bearing on the linguistic relativity hypothesis. In many studies demonstrating language effects, such as that of Lucy (1993), participants linguistically encoded the stimuli before giving responses to nonlinguistic tasks, or else did so during the task (for example, by providing pictures with labels). Given that we did not find language effects after non-linguistic encoding, language effects in previous studies may not have been present if the order of the linguistic and nonlinguistic tasks had been reversed.

Finally, our results speak directly to research in the domain of motion events. Although our findings are partially consistent with the weaker formulations of Slobin (1996a,b, 1997), the fact that no language effect was found in recognition memory, even when verbal encoding was elicited experimentally, indicates that the cognitive consequences of the typology on memory representations are minor. Thinking for speaking did not have a detectable effect in recognition. Only the similarity data showed a linguistic effect of the sort suggested by Slobin, i.e. a differential effect of Spanish vs. English on use of manner vs. path dimensions. However, the effect may reflect a conscious or unconscious strategy adopted by speakers, where they solved a difficult judgment by appealing to the visual dimension(s) or features made salient by their descriptions in the context of the task. Although the mental representations entertained during the task may have been different for speakers of each language, these dimension(s) are not necessarily more prominent in speakers' non-linguistic mental representations of ordinary events. Under this interpretation, Jackendoff's universalist view may still be correct, because it concerns abstract conceptual representations, not task-specific ones. Thus, despite the possibility of linguistic influences on cognitive tasks, our results may be explained without positing differences between the stable mental representations entertained by speakers in ordinary language use.

\section{Conclusions}

In this study, we asked whether different lexicalization patterns in English and Spanish have cognitive significance for the speakers of these languages. We addressed this ques- 
tion by analyzing performance on two non-linguistic tasks, recognition memory and similarity judgments of motion events, and participants' linguistic descriptions. We varied the initial encoding of motion events to be either linguistic or non-linguistic before testing for recognition and similarity. No effect of language in the recognition memory task was observed after either linguistic or non-linguistic encoding. There was also no effect of language in the similarity task after non-linguistic encoding. This suggests that linguistic and conceptual representations are separate and dissociable. However, a linguistic effect in the similarity task after linguistic encoding did occur: the linguistic encoding prompted responses consistent with the linguistic patterns. Linguistic descriptions directed attention to certain aspects of the events later used to make a non-linguistic judgement. This finding shows the need to consider the relative order of linguistic and non-linguistic tasks in studies of the linguistic relativity hypothesis, and suggests that although linguistic and non-linguistic tasks are dissociable, language-specific regularities available in the experimental context may mediate speakers' performance in making non-linguistic judgments.

\section{Acknowledgements}

This work was supported by NIMH Grant MH51271 to Barbara Malt and Steven Sloman. We thank Dan Slobin and Lawrence Barsalou for helpful comments on a previous version of this paper, and Pauline Jacobson and William Warren for wonderful support. We are also in debt to Gerry Altmann for insightful suggestions on the implications of our findings.

\section{References}

Aske, J. (1989). Path predicates in English and Spanish: a closer look. Proceedings of the Fifteenth Annual Meeting of the Berkeley Linguistics Society (pp. 1-14). Berkeley, CA: Berkeley Linguistics Society.

Barsalou, L. (1992). Cognitive psychology: an overview for cognitive scientists. Hillsdale, NJ: Erlbaum Associates.

Berlin, B., \& Kay, P. (1969). Basic color terms: their universality and evolution, Berkeley, CA: University of California Press.

Billman, D., \& Krych, M. (1998). Path and manner verbs in action: effects of "Skipping" or "Exiting" on event memory. Proceedings of the 20th Annual Conference of the Cognitive Science Society. Hillsdale, NJ: Lawrence Erlbaum Associates.

Billman, D., Swilley, A., \& Krych, M. (2000). Path and manner priming: verb production and event recognition. Proceedings of the 22nd Annual Conference of the Cognitive Science Society. Hillsdale, NJ: Lawrence Erlbaum Associates.

Bingham, G. (1985). Dynamics and the problem of visual event recognition. In T. Prot \& T. van Gelder (Eds.), Mind as motion: dynamics, behavior and cognition. Cambridge, MA: MIT Press.

Bingham, G., Schmidt, R., \& Rosenblum, L. (1995). Dynamics and the orientation of kinematic forms in visual event recognition. Journal of Experimental Psychology: Human Perception and Performance, 21, 14731493.

Bloom, A. H. (1981). The linguistic shaping of thought: a study in the impact of language on thinking in China and the West. Hillsdale, NJ: Erlbaum Associates.

Bowerman, M. (1996). The origins of children's spatial semantic categories: cognitive versus linguistic determinants. In J. Gumperz \& S. Levinson (Eds.), Rethinking linguistic relativity. Cambridge: Cambridge University Press. 
Brown, R., \& Lenneberg, E. (1954). A study in language and cognition. Journal of Abnormal and Social Psychology, 49, 454-462.

Brown, P., \& Levinson, S. (1993). "Uphill” and "Downhill” in Tzeltal. Journal of Linguistic Anthropology, 3, 4674.

Choi, S., \& Bowerman, M. (1991). Learning to express motion events in English and Korean: the influence of language-specific lexicalization patterns. Cognition, 41, 83-121.

Comrie, B. (1981). Language universals and linguistic typology: syntax and morphology, Chicago, IL: University of Chicago Press.

Davidoff, J., Davies, I., \& Roberson, D. (1999). Color categories in a stone-age tribe. Nature, 398, 203-204.

Dowty, D. (1979). Word meaning and Montague grammar. Dordrecht: Kluwer.

Dowty, D. (1986). The effects of aspectual class on the temporal structure of discourse: semantics or pragmatics? Linguistic and Philosophy, 9, 37-61.

Goldstone, R. (1994). Influences of categorization on perceptual discrimination. Journal of Experimental Psychology: General, 123, 178-200.

Goldstone, R. (1994). The role of similarity in categorization: providing a groundwork. Cognition, 52, 125-157. Goodman, N. (1955). Fact, fiction, and forecast. Cambridge, MA: Harvard University Press.

Greenberg, J. (1966). Language universals. In T. Sebeok, Theoretical foundations. Current trends in linguistics (pp. 61-112), III. The Hague: Mouton.

Hayward, G., \& Tarr, M. (1995). Spatial language and spatial representation. Cognition, 55, 39-84.

Heider, E.R. (1971). "Focal" color areas and the development of names. Developmental Psychology, 4, 447-455.

Heider, E.R. (1972). Universals in color naming and memory. Journal of Experimental Psychology, 93, 10-20.

Heider, E.R., \& Olivier, D. (1972). The structure of the color space in naming and memory for two languages. Cognitive Psychology, 3, 337-354.

Hermer-Vazquez, L., Spelke, E. S., \& Katsnelson, A. S. (1999). Source of flexibility in human cognition: dualtask studies of space and language. Cognitive Psychology, 39, 3-36.

Jackendoff, R. (1986). Semantics and cognition. Cambridge, MA: MIT Press.

Jackendoff, R. (1990). Semantic structures. Cambridge, MA: MIT Press.

Jackendoff, R. (1996). The architecture of the linguistic-spatial interface. In P. Bloom, M. Peterson \& M. Garrett (Eds.), Language and space. Cambridge, MA: MIT Press.

Kay, P., \& Kempton, W. (1984). What is the Sapir-Whorf hypothesis? American Anthropologist, 86, 65-79.

Kay, P., \& McDaniel, C. (1978). The linguistic significance of the meanings of basic color terms. Language, 54, 610-646.

Kurtz, K. (1996). Category-based similarity. Proceedings of the Eighteenth Annual Conference of the Cognitive Science Society. Hillsdale, NJ: Erlbaum.

Landau, B., \& Jackendoff, R. (1993). "What" and "where" in spatial language and spatial cognition. Behavioral and Brain Sciences, 16, 217-238.

Lantz, D., \& Stefflre, V. (1964). Language and cognition revisited. Journal of Abnormal and Social Psychology, $69,472-481$.

Lenneberg, E., \& Roberts, J. (1956). The language of experience: a study in methodology. International Journal of American Linguistics, 22, 2 part 2, Memoir 13.

Levin, B., \& Rappaport Hovav, M. (1992). The lexical semantics of verbs of motion: the perspective from unaccusativity. In I. Roca (Ed.), Semantic structure: its role in grammar. Berlin: Mouton de Gruyter.

Levinson, S. (1994). Vision, shape, and linguistic description: Tzeltal body-part terminology and object description. Linguistics, 32, 791-855.

Levinson, S. (1996a). Relativity in spatial conception and description. In J. Gumperz \& S. Levinson (Eds.), Rethinking linguistic relativity. Cambridge: Cambridge University Press.

Levinson, S. (1996b). Frames of reference and Molyneux's question: crosslinguistic evidence. In P. Bloom, M. Peterson \& M. Garrett (Eds.), Language and space. Cambridge, MA: MIT Press.

Levinson, S. (1997). From outer to inner space: linguistic categories and non-linguistic thinking. In J. Nuyts \& E. Pederson (Eds.), Language and Conceptualization (pp. 14-45). Cambridge, MA: MIT Press, .

Lucy, J. (1992). Language diversity and thought. Cambridge: Cambridge University Press.

Lucy, J. (1993). Grammatical categories and cognition. Cambridge: Cambridge University Press.

Lucy, J. (1996). The scope of linguistic relativity: an analysis and review of empirical research. In J. Gumperz \& S. Levinson (Eds.), Rethinking linguistic relativity. Cambridge: Cambridge University Press. 
Malt, B., Sloman, S., Gennari, S., Shi, M., \& Wang, Y. (1999). Knowing versus naming: similarity and the linguistic categorization of artifacts. Journal of Memory and Language, 40, 230-262.

Mandler, G. (1980). Recognizing: the judgment of previous occurrence. Psychological Review, 87, 252-271.

Medin, D., Goldstone, R., \& Gentner, D. (1993). Respects for similarity. Psychological Review, 100, 254-278.

Naigles, L., Eisenberg, A., Kako, E., Highter, M., \& McGraw, N. (1998). Speaking of motion: verb use in English and Spanish. Language and Cognitive Processes, 13, 521-549.

Papafragou, A., Massey, C. \& Gleitman, L. (2001). Shake, rattle ' $n$ ' roll: the representation of motion in language and cognition. Manuscript submitted for publication. University of Pennsylvania.

Rajaram, S. (1993). Remembering and knowing: two means of access to the personal past. Memory and Cognition, 21, 89-102.

Roberson, D., Davies, I., \& Davidoff, D. (2000). Color categories are not universal: replication and new evidence from a stone-age culture. Journal of Experimental Psychology: General, 129, 369-398.

Rothbart, M., Davis-Stitt, C., \& Hill, J. (1997). Effects of arbitrarily placed category boundaries on similarity judgments. Journal of Experimental Social Psychology, 33, 122-145.

Sera, M., Berge, A., \& Pintado, J. (1994). Grammatical and conceptual forces on the attribution of gender by English and Spanish speakers. Cognitive Development, 9, 261-292.

Slobin, D. (1996). Two ways of travel: verbs of motion in English and Spanish. In M. Shibatani \& S. Thompson (Eds.), Grammatical constructions: their form and meaning. Oxford: Clarendon Press.

Slobin, D. (1996). From "thought and language" to "thinking for speaking”. In J. Gumperz \& S. Levinson (Eds.), Rethinking linguistic relativity. Cambridge: Cambridge University Press.

Slobin, D. (1997). Mind, code, and text. In J. Bybee, J. Haiman \& S. Thompson (Eds.), Essays on language function and language type. Amsterdam: John Benjamins.

Slobin, D. (1998). Verbalized events: a dynamic approach to linguistic relativity and determinism. Working Papers for the LAUD Symposium, Essen: Linguistic Agency University-GH Essen.

Sloman, S. A. (1996). The empirical case for two systems of reasoning. Psychological Bulletin, 119, 3-22.

Talmy, L. (1983). How language structures space. In H. Pick \& L. Acredolo (Eds.), Spatial orientation: theory, research and application. New York: Plenum Press.

Talmy, L. (1985). Lexicalization patterns: semantic structure in lexical forms. In T. Shopen (Ed.), Grammatical categories and the lexicon. Language typology and syntactic description (pp. 57-149). 3. Cambridge: Cambridge University Press.

Todd, J. (1983). Perception of gait. Journal of Experimental Psychology: Human Perception and Performance, 1, $31-42$.

Tversky, A. (1977). Features of similarity. Psychological Review, 84, 327-352.

Tversky, A., \& Gati, I. (1978). Studies of similarity. In E. Rosch \& B. Lloyd (Eds.), Cognition and categorization. Hillsdale, NJ: Erlbaum.

Whorf, B. (1956). In J. Carroll, Language, thought, and reality: selected writings of Benjamin Lee Whorf. Cambridge, MA: MIT Press.

Zhang, S., \& Schmitt, B. (1998). Language-dependent classification: the mental representation of classifiers in cognition, memory, and ad evaluations. Journal of Experimental Psychology: Applied, 4, 375-385. 